\title{
Short preface
}

\section{Memory with Prof. Michel Che}

\section{Takekazu Ishida $^{1}$}

Received: 10 June 2020 / Accepted: 12 June 2020 / Published online: 9 November 2020

(c) Springer Nature B.V. 2020

I felt deep sorrow to learn that Professor Michel Che passed away on August 7, 2019. I would like to express my heartfelt condolences to his family, his colleagues and the communities that he was a part of. I became acquainted with Professor Che through the NanoSquare program at Osaka Prefecture University. This program was subsidized by the Ministry of Education, Culture, Sports, Science and Technology from 2008 with the aim of fostering an outstanding institute for developing human resources in academia. Professor Che was one of the most active external committee members of the NanoSquare program over the 11 years that I served as a program officer. I heard from Professor Che that, although he had many experiences serving on assessment committees across the globe, it was the first time for him to witness how committee choices made over many years affected the birth and growth of a research institute. It is a matter of fact that he behaved faithfully as a member of the committee, always bringing a thick notebook to leave anything on record. Eighteen young scientists were employed as tenure-track faculty members, and it must have been a great joy for him to watch as many of them advanced to tenure and began their professional careers as indispensable members of the University. Some of them are authors of papers in this special issue. Professor Che was respected as one of the most accomplished professors in the field of catalysis. I found it impressive that he was able to give valuable advice to people working across physics, chemistry and engineering. He offered advice to others not only with deep insight but also with a sense of wit, humor and a friendly smile. I am sincerely pleased to know that his achievements will be handed down to future generations through this special issue, dedicated to Professor Che, edited by Professor Masakazu Anpo.

Takekazu Ishida

ishida@center.osakafu-u.ac.jp

1 Osaka Prefecture University, Osaka 599-8531, Japan 


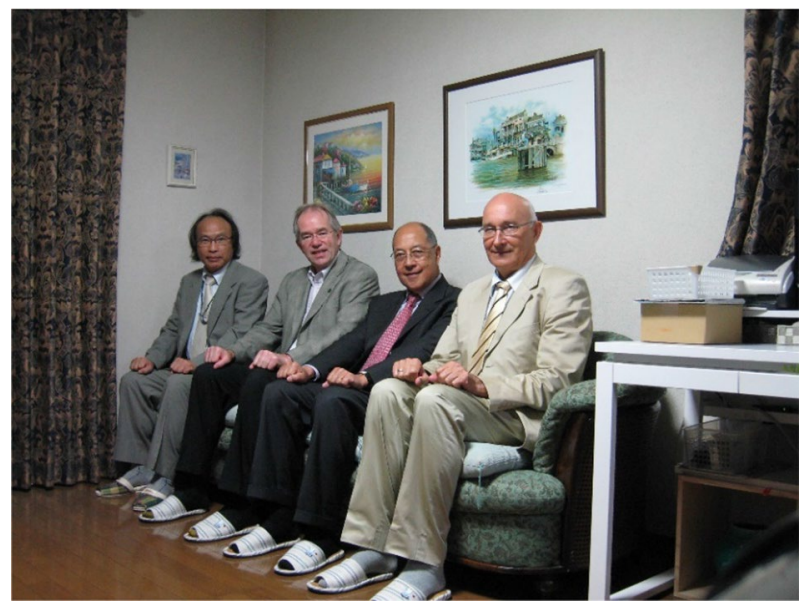

With Prof. Michel Che (second from right), Prof. Victor V. Moshchalkov (Leuven, Belgium) (right end), Prof. Robert Magnusson (Texas, USA) (third from right) and me (Prof. Takekazu Ishida) (left end) in my house

Publisher's Note Springer Nature remains neutral with regard to jurisdictional claims in published maps and institutional affiliations. 